\title{
BMJ Open Hepatitis B virus contact disclosure and testing in Lusaka, Zambia: a mixed- methods study
}

\author{
Sarah Franklin, ${ }^{1}$ Amina Mouliom, ${ }^{2}$ Edford Sinkala, ${ }^{3,4}$ Annie Kanunga, ${ }^{3}$ \\ Anna Helova, ${ }^{1}$ Jodie Dionne-Odom, ${ }^{5}$ Janet M Turan, ${ }^{1}$ Michael Vinikoor ${ }^{3,5}$
}

To cite: Franklin S, Mouliom A, Sinkala $\mathrm{E}$, et al. Hepatitis B virus contact disclosure and testing in Lusaka, Zambia: a mixedmethods study. BMJ Open 2018;8:e022522. doi:10.1136/ bmjopen-2018-022522

- Prepublication history and additional material for this paper are available online. To view these files, please visit the journal online (http://dx.doi. org/10.1136/bmjopen-2018022522).

SF and AM contributed equally.

Received 6 March 2018 Revised 26 July 2018 Accepted 1 August 2018

\section{Check for updates}

(c) Author(s) (or their employer(s)) 2018. Re-use permitted under CC BY-NC. No commercial re-use. See rights and permissions. Published by BMJ.

${ }^{1}$ School of Public Health, University of Alabama at Birmingham, Birmingham, Alabama, USA

${ }^{2}$ School of Pharmacy, Southwestern Oklahoma State University, Weatherford, Oklahoma, USA

${ }^{3}$ Tropical Gastroenterology and Nutrition Group, University of

Zambia, Lusaka, Zambia

${ }^{4}$ Department of Medicine, University Teaching Hospital, Lusaka, Zambia

${ }^{5}$ Department of Medicine, University of Alabama at Birmingham, Birmingham, Alabama, USA

Correspondence to Dr Michael Vinikoor; michaelvinikoor@uabmc.edu

\section{ABSTRACT}

Objectives The aim of this study was to estimate the frequency of disclosure to and testing of contacts of patients with hepatitis B virus (HBV) in Zambia.

Design We used a convergent parallel mixed-method research design including a quantitative survey and focus group discussions with patients with HBV.

Setting A university hospital in Lusaka, Zambia.

Participants 79 hepatitis B surface antigen (HBsAg)positive, HIV-negative, adults (18+ years) receiving HBV care completed a quantitative survey and 32 also participated in a focus group discussion.

Outcomes and analysis Contacts of patients with HBV were enumerated and patient-reported disclosure, contact testing and contact HBV test results were used to develop a testing cascade. Using multivariable logistic regression, we identified factors associated with disclosure of HBV status. In focus groups, we explored how index patient knowledge and awareness of their condition shaped perspectives on contact disclosure and testing. Focus groups coding and analysis followed a thematic analysis approach.

Results Among 79 patients with HBV (median age 35 years; $26.6 \%$ women), the majority reported disclosure to $\geq 1$ contact. According to the index patients' knowledge, of 776 contacts enumerated, 326 (42.1\%) were disclosed to, $77(9.9 \%)$ were tested, $67(8.6 \%)$ received results and 8 (11.9\%) were HBsAg-positive. Increased stigma score was associated with reduced disclosure. In focus groups, HBV awareness, knowledge and stigma emerged as barriers to disclosure and referral of contacts for testing. Association of HBV with HIV-related stigma was also reported as a strong barrier to contact disclosure and testing and to taking antivirals for HBV monoinfection.

Conclusions HBV contact disclosure and testing were feasible and yielded new diagnoses in Zambia. A better understanding of barriers to seeking HBV testing and treatment is needed to scale-up this important intervention in Africa.

Trials registration number NCT03158818.

\section{INTRODUCTION}

Chronic hepatitis B virus (HBV) is a major worldwide cause of morbidity and mortality, with sub-Saharan Africa and Asia most affected. An estimated 887000 persons die each year due to HBV-related inflammation

\section{Strengths and limitations of this study}

- This is the one of the first studies in Africa to evaluate hepatitis B virus (HBV) disclosure and contact testing.

- We explored HBV knowledge, awareness and stigma as major barriers to HBV status disclosure, contact testing and uptake of antiviral therapy using a mixed-methods approach.

- We described an HBV testing cascade based on reported disclosure and contact testing.

- Quantitative data on HBV disclosure and contact testing relied on patient report that is subject to social desirability, recall biases, as well as inaccuracy as some contacts may have taken an HBV test without the knowledge of the index patient.

of the liver, cirrhosis and/or hepatocellular carcinoma $^{1-3}$ and deaths from viral hepatitis have risen in the past 20 years. ${ }^{4}$ In high-income settings, most chronic hepatitis B (CHB) cases are imported from Africa and Asia, making HBV a global public health problem. ${ }^{5}$ Although inexpensive antiviral therapies are available, the majority of patients with $\mathrm{CHB}$ are unaware of their status. ${ }^{6}$ In high seroprevalence settings, WHO recommends general population testing where all unvaccinated adults should be tested. ${ }^{7}$ A recent study conducted in Gambian villages demonstrated the feasibility of testing adults for HBV using a rapid point-of-care assay, followed by linkage to antiviral therapy. ${ }^{8}$

In addition to testing in the general population, focused HBV testing among most-affected populations including contacts (sexual partners, children and other family and household members) to those with HBV infection is recommended. ${ }^{910}$ Contact testing can reduce costs and more efficiently find new cases compared with general population testing but has a number of potential obstacles. First, if general knowledge and awareness of HBV is low in the population, patients disclosing their status to contacts may face 
stigma similar to that experienced with disclosure of other sexually transmitted infections. ${ }^{11-15}$ In patients with CHB in Asia and among immigrant groups in the USA, self-stigma undermined engagement in HBV care and thus could reduce contact testing efforts. ${ }^{16-19}$

To better understand the feasibility and barriers to HBV contact testing in the African context, we performed a cross-sectional mixed-methods study with HBV monoinfected adults in Zambia. Zambia has $5.6 \%$ adult prevalence of hepatitis B surface antigen (HBsAg)-positivity and national guidelines on HBV treatment were established..$^{20}$ We surveyed patients with $\mathrm{HBV}$ receiving care at a referral hospital to assess disclosure of HBV status to contacts and subsequent $\mathrm{HBV}$ testing among contacts. We also measured HBV knowledge and stigma. To complement the survey, we conducted focus groups with patients to understand perspectives on CHB infection in Zambia, as well as disclosure to and testing of contacts. Zambia also has a generalised HIV epidemic and partner disclosure was reported by $80 \%-90 \%$ of patients. ${ }^{21}$ We therefore hypothesised that disclosure of HBV to spouses would be common. Also based on our experience in HIV care, we hypothesised that low HBV knowledge and increased stigma would be associated with lower disclosure of $\mathrm{HBV}$ status.

\section{METHODS}

\section{Hepatitis B UTH cohort study}

In 2016, a clinical cohort study was created at University Teaching Hospital (UTH) in Zambia's capital Lusaka to characterise CHB infection and inform national and regional policy. UTH is the largest public sector hospital in the country, with approximately 400000 outpatient visits and 90000 admissions per year. Within the Department of Medicine, care is provided for an estimated 300 patients with HBV per year and the Ministry of Health has established national guidelines on the use of antiviral therapy for $\mathrm{HBV}^{20}$ which were largely adapted from the WHO recommendations. During August 2016 to July 2017, consecutive outpatients within the Department of Medicine were recruited if they were HBsAg-positive, HIV-negative and $18+$ years. Those who were unlikely to be retained due to residence outside of Lusaka or severe medical illness were excluded from participation. Written informed consent was obtained. Management of HBV continued according to national policies. At enrolment, we captured patient demographic and clinical data, extracted available medical records and collected blood to measure routinely recommended HBV markers. ${ }^{22} \mathrm{We}$ documented the presence/absence of liver disease signs and symptoms and measured baseline HBV knowledge using six true-false questions adapted from a survey in China. ${ }^{23}$ Follow-up visits occurred every 3-6 months, and transportation costs based on distance from home to clinic were reimbursed at each visit up to 48 months after enrolment to reduce structural barriers to retention. Counselling and health education was provided at all visits, including the specific recommendation that participants disclose their HBV status to and refer their sexual partners, first-degree relatives and household members for HBsAg testing, ${ }^{24}$ available for free at UTH as well as at other public health facilities. HBV vaccination, which is not free in Zambia (and costs US\$5-10 per dose), was recommended for contacts who tested HBsAg-negative. Over the first year of the cohort, 140 patients enrolled and retention was relatively high $(85 \%) 1$ year later.

\section{Patient involvement}

Although patients were not directly involved in the design of this study, the development of research question and outcome measures for this study was based on interactions while providing care to the HBV patient cohort. Patients were not involved in the recruitment and conduct of the study. Results have been disseminated to study participants through informational sessions held with HBV cohort members every 3-6 months.

\section{Mixed-methods evaluation of contact HBV testing}

A convergent parallel mixed-method research design was used to evaluate the uptake and outcomes of HBV contact testing. ${ }^{25}$ As part of a student-led research initiative during May-July 2017, we asked a convenience sample of cohort participants to provide the age and sex of up to 20 living contacts who needed HBsAg testing per public health guidelines. Contacts were defined as living first-degree blood relatives (parents, children, siblings), current sexual partners or any other persons currently living in the same household as the index patient. For each contact mentioned we asked whether that person was made aware of the index patient's HBV status (ie, were disclosed to). Among contacts who were informed of the index patient's status, we determined the proportion who went for HBsAg testing, received results and were HBsAg-positive according to the index patient's knowledge. We did not document uptake of vaccination among contacts who tested HBsAg-negative. We also administered the Stigma Scale for Chronic Illness, an eight-item instrument that assesses enacted and internalised stigma, ${ }^{26}$ adapted for HBV. The scale used a five-level Likert scale for each item. Each stigma item was weighted equally and Likert responses were coded numerically $(0-4)$ with more points suggestive of greater stigma. The summed score range for this scale was $0-32$.

To contextualise survey data, we also performed five sex-stratified (three with women, two with men) focus group discussions (FGDs) including a total of 32 cohort participants (4-9 participants per group; 16 women and 16 men overall). FGDs were optional for cohort participants, and we recruited those in the cohort that were due for study follow-up visits and could be reached by phone. Patients were allowed to both join an FGD and complete the survey. FGDs were conducted in private settings in English or local Zambian language. Participant characteristics were linked to the qualitative data. A focus group guide included discussion about HBV, knowledge and 
awareness of $\mathrm{HBV}$ in the community and among healthcare workers, barriers and facilitators to HBV testing of partners and blood relatives, and linkage to care. Moderators (one male and two females), fluent in English and/or a local Zambian language, underwent additional training in qualitative research methods and the study topics prior to the initiation of the study.

\section{Data analysis \\ Quantitative}

We described the sociodemographic and clinical characteristics of index patients who participated in the survey and the proportion who reported disclosure of HBV status to at least one contact. We compared the odds of disclosure by contact type (sexual partners vs relatives vs other household members) using logistic regression. In a univarable analysis, we tested the association of index patient age, sex, education level (categorised as none, $0-6$ $7-8,9-12$ and $>12$ th grade), liver signs/symptoms, HBV knowledge score and stigma score with disclosure to at least one contact. In a multivariable analysis, we identified available factors collected on contacts (age, sex and relationship to index patient) that were associated with HBV testing among those who were disclosed to. To visualise the challenges and successes in HBV contact testing, we created an HBV testing cascade from awareness to testing, results receipt and finally HBsAg status. ${ }^{27}$

\section{Qualitative}

FGDs were digitally recorded, translated to English when necessary and transcribed verbatim, excluding any identifying information. All files were password-protected and stored in a secure location. Subsequently transcripts were coded using the Dedoose qualitative software program (SocioCultural Research Consultants). Coding and analysis followed a thematic analysis approach. ${ }^{28}{ }^{29}$ The coding framework was based on the literature, topics from interview guide and emerging themes from transcripts. Transcripts were initially broad-coded by two individuals trained in qualitative coding. Consistency of coding between two individuals was established through frequent discussion between coders until consistency was fully established. Excerpts from broad codes were then fine-coded using an inductive approach by the same coders. Additional themes were allowed to emerge from the data, and major themes were refined and subthemes identified.

\section{RESULTS}

We enrolled 140 participants in the HBV cohort. Evaluation of contact testing was performed during May-July 2017 and $79(56.4 \%)$ index patients completed the quantitative survey. Among index patients completing the survey, median age was 35 years (IQR, 27-45), 21 (26.6\%) were women and 15 (19.2\%) had signs/symptoms of liver disease (table 1). Median educational attainment was grade 9-12 and those with $0-8$ th grade education were
Table 1 Characteristics of patients with chronic hepatitis $B$ infection who participated in contact testing survey in Lusaka, Zambia

\begin{tabular}{|c|c|c|c|}
\hline & $\begin{array}{l}\text { Overall } \\
(n=79)\end{array}$ & $\begin{array}{l}\text { Men } \\
(n=58)\end{array}$ & $\begin{array}{l}\text { Women } \\
(n=21)\end{array}$ \\
\hline \multicolumn{4}{|l|}{ Age in years, $n(\%)$} \\
\hline 18-29 & $26(32.9)$ & $20(34.5)$ & $6(28.6)$ \\
\hline $30-39$ & $24(29.3)$ & $17(29.3)$ & $7(33.3)$ \\
\hline $40+$ & $29(36.7)$ & $21(36.2)$ & $8(38.1)$ \\
\hline \multicolumn{4}{|c|}{ Monthly household income, $\mathrm{n}(\%)^{\star}$} \\
\hline$<2000$ & $27(34.6)$ & $18(31.6)$ & $9(42.9)$ \\
\hline $2000-5000$ & $30(38.5)$ & $24(42.1)$ & $6(28.6)$ \\
\hline$>5000$ & $17(21.8)$ & $14(24.6)$ & $3(14.3)$ \\
\hline \multicolumn{4}{|l|}{ Educational level, $n(\%)$} \\
\hline None to 6th grade & $19(24.4)$ & $8(14.0)$ & $11(52.4)$ \\
\hline 7th to 12 th grade & $21(26.9)$ & $16(28.1)$ & $5(23.8)$ \\
\hline College & $38(48.7)$ & $33(57.9)$ & $5(23.8)$ \\
\hline $\begin{array}{l}\text { Signs/symptoms of liver } \\
\text { disease at hepatitis B } \\
\text { virus diagnosis, } n(\%)\end{array}$ & 15 (19.2) & $11(19.3)$ & $4(19.0)$ \\
\hline $\begin{array}{l}\text { Median stigma score } \\
\text { (IQR) }\end{array}$ & $9(4-13)$ & $9(6-13)$ & $6(3-10)$ \\
\hline
\end{tabular}

*In Zambian kwacha. At time of survey, US\$1 was equivalent to 8.5 kwacha.

collapsed into one category for analysis. From the 79, we enumerated 776 contacts (mean of 9.8/index patient) that should be tested for HBV per public health recommendations including 66 sexual partners (40 spouses, 26 other partners), 604 first-degree blood relatives (mean 7.7/patient) and 105 other household members (mean $1.3 /$ patient).

Barriers to HBV status disclosure to contacts, contact testing, treatment and prevention in Zambia

Disclosure

Disclosure to at least one contact was reported by 70 $(88.6 \%)$ index patients who participated in the survey, and most $(n=56 ; 70.9 \%)$ disclosed to more than one contact. However, overall less than half $(42.1 \%)$ of contacts listed were disclosed to at the time of our survey. Among the 326 contacts made aware of potential HBV exposure, $77(23.6 \%)$ had been tested for HBsAg according to the index patient, the majority $(67$ of $77 ; 87.0 \%)$ received their test results and 8 of $67(11.9 \%)$ were reported to be HBsAg-positive (figure 1). Notably index patients reported a high level of disclosure to their sexual partners who were spouses (35 of 40 spouses; 87.5\%). After adjustment for the age and sex of the contact, the odds of disclosure were increased for sexual partners (adjusted OR (AOR), 6.06; 95\% CI 3.01 to 12.16) and first-degree relatives (AOR, $1.57 ; 95 \%$ CI 0.98 to 2.50 ) compared with other household members (figure 2). Among the subset of contacts who were disclosed to, those aged $>40$ years 


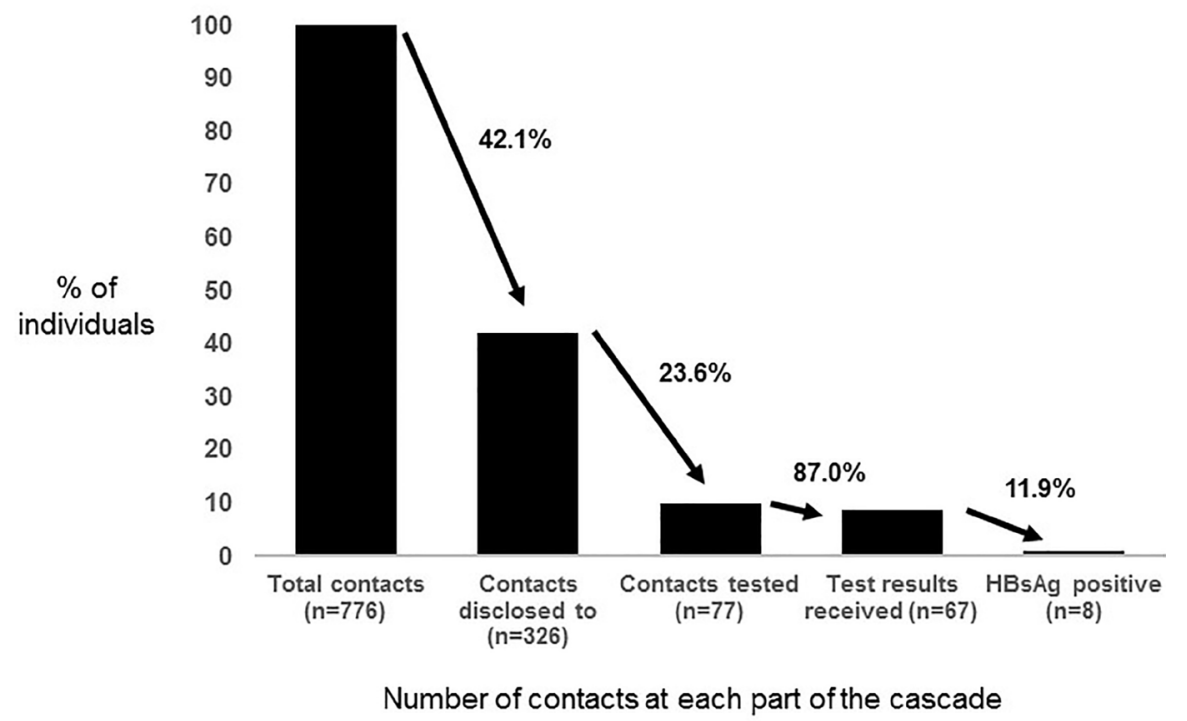

Figure 1 Hepatitis B testing cascade among contacts to hepatitis B surface antigen (HBsAg)-positive Zambian adults.

had lower odds of being tested (AOR, 0.24; $95 \%$ CI 0.08 to 0.75$)$ compared with contacts $<18$ years. Also, the relationship to the index patient was associated with odds of contact testing with spouses (AOR, 8.10; 95\% CI 3.30 to 19.86 ) and parents (AOR, 3.21; 95\% CI 1.11 to 9.26 ) being more likely and children being less likely (AOR, $0.37 ; 95 \%$ CI 0.15 to 0.94 ) to test compared with the reference group (siblings).

These findings were further contextualised by findings from the FGDs. The majority of participants reported difficulties with disclosure of their HBsAg-positive status, and few disclosed to persons other than their partner and closest family members. The most commonly reported barriers to disclosure were stigma related to $\mathrm{HBV}$, the perceived association with HIV, assumed promiscuity and related fears of the consequences of disclosure, for example, impacts on couple and family relationships.
I only disclosed to my children. And to others I can't even disclose because I'm so scared that they can laugh at me, they can avoid me, they can talk about me behind my back. (Female, age 51)

Apart from my husband no one knows that I come here for hepatitis because there is stigma and they know that this thing is infectious. Just like my sister [other participant] there, it is sad that the husband left because she was put on treatment ART. (Female, age 30 )

\section{Low awareness and knowledge of HBV}

Low HBV knowledge and awareness among patients was observed in both surveys and FGDs. In the survey (supplementary table 1), despite their HBV-positive status and relatively high education levels $(40 \%$ had some college education), $38 \%$ answered one or more HBV knowledge

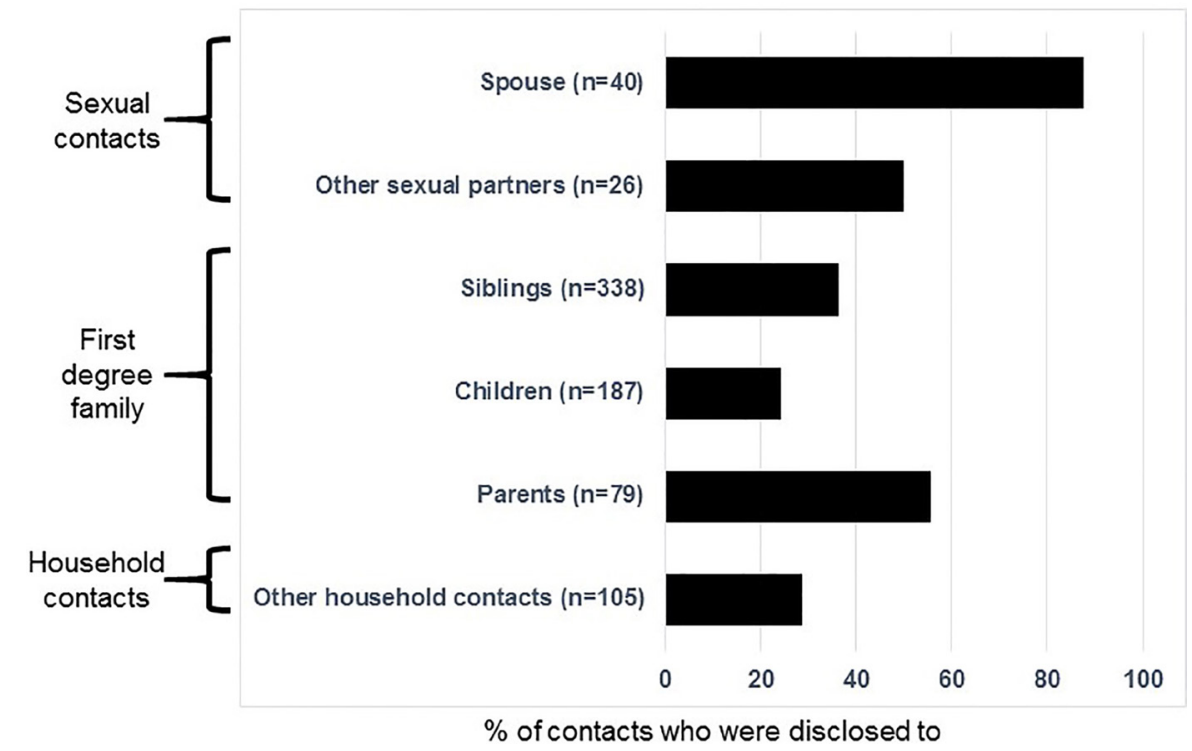

Figure 2 Disclosure of chronic hepatitis B status to contacts according to relationship with the index case. 
questions incorrectly. The items answered incorrectly most often were 'HBV is transmitted by mosquitoes' and 'HBV can be spread by shaking hands'.

During FGDs, the low awareness of HBV in communities and among healthcare providers was frequently discussed. The majority of participants reported to have learnt their HBV status when attempting to donate blood. FGD participants attested to the fact that people in the community know very little about hepatitis or have even not heard about it.

The time when she found out that she had Hepatitis $\mathrm{B}$, it was easy for her to accept because she did not have any information about Hepatitis B. (Female, age 51)

HBV seems to be perceived as a less serious health concern compared with HIV; however, its association with HIV appears to generate concerns among those tested and disclosed.

My family knows nothing at all really so I realized. In fact, they came to know about it [Hepatitis] after I told them about it. I didn't even know it was there until I was diagnosed with it. When I explained to them that it's transmitted most like AIDS they got scared. And when I told them that there would be a point when one has to take medications just like AIDS that scared them even more. (Male, age 18)

Moreover, in FGDs, participants often expressed concern over limited awareness and knowledge of HBV among healthcare workers.

This disease is more like a silent killing disease. Even some of the clinical workers they don't know about this disease so it's, it's very difficult for the community to know about this. (Male, age 27)

When my mother was discovered that she had hepatitis that's when we asked the people who works at the clinic, they were very surprised [...]. You should bring her back to the doctor who tested it didn't know the medication he had administered, this medication is for people who have HIV not for hepatitis. (Female, age 55)

Lack of knowledge seemed to negatively affect the willingness to get tested for HBV. Lack of willingness to get tested for $\mathrm{HBV}$ was mentioned due to its association with HIV, fears of the unknown and feelings of fatality if diagnosed with HBV.

It's better I die without knowing about it than knowing my status. (Female, age 45)

Additionally, in health services, testing and linkage to care for HIV-positive patients seem to be often prioritised over HBV testing.

When you go to clinic they don't even test you for Hepatitis B, their only concern is about HIV. (Male, age 27)
Table 2 Univariable factors associated with disclosure of hepatitis B virus (HBV) infection status to at least one contact

\begin{tabular}{ll}
\hline & Unadjusted OR $(\mathbf{9 5 \%} \mathbf{C l})$ \\
\hline Age, per 5-year increase & $0.98(0.74$ to 1.29$)$ \\
\hline $\begin{array}{l}\text { Female sex } \\
\text { Education level }\end{array}$ & $3.20(0.38$ to 27.27$)$ \\
\hline \multicolumn{1}{c}{ None to grade 8} & Reference \\
\multicolumn{1}{c}{ Grades $9-12$} & $0.71(0.10$ to 4.76$)$ \\
College & $1.00(0.17$ to 6.01$)$ \\
Signs/symptoms of liver disease & $0.81(0.15$ to 4.37$)$ \\
HBV knowledge score, per one- & $1.04(0.44$ to 2.50$)$ \\
unit increase & \\
\hline $\begin{array}{l}\text { Stigma score, per one-unit } \\
\text { increase }\end{array}$ & $0.87(0.78$ to 0.98$)$ \\
\hline
\end{tabular}

Stigma

The median stigma score was 9 (IQR 4-13) and in bivariable analysis, men had higher median stigma scores than women (9 vs $6 ; \mathrm{p}=0.02$ ) but other patient factors (age, income, education, presence of liver signs/symptoms) were not associated with stigma score. A one-unit increase in stigma score was associated with a $12 \%$ reduction in the odds of disclosing to anyone (OR $0.87 ; 95 \%$ CI 0.78 to 0.98 ; table 2 ).

In FGDs, stigma was also one of the most discussed barriers to HBV disclosure and testing, related to low knowledge, the association with HIV and assumptions of promiscuity as the most likely mode of transmission. A few HBV-positive health care workers (HCWs) emphasised that they thought they had been infected through job-related injury.

When I told my wife that I've been diagnosed with hepatitis, then it came in the mind quickly that I think you are promiscuous. The element of promiscuity came in, and I was stigmatized. It was very bad until I had to bring my wife to the nurse for some counseling and assurance that it's not as you think. Since this man works in an environment where he handles a lot of patient samples in the laboratory, this could be the very much area this disease could have come in. (Male, age 45)

As for me I was just saved by my career, because if I wasn't a nurse people would have thought it [HBV] was sexually transmitted. (Female, age 30)

HBV's association with HIV in the Zambian context was frequently mentioned in the FGDs as a barrier to testing as well as a source of stigma. Participants believed that HBV treatment is effective; however, the drugs prescribed for HBV treatment are also used for HIV creating an associated stigma. For example, many stated that if others discovered a person with an antiretroviral (ART therapy for HIV) medication bottle such as Truvada (fixed dose combination tenofovir disoproxil fumarate with 
emtricitabine or lamivudine), then that person would be stigmatised as if they have HIV. One patient even stated that her husband left her when she was initiated on antiviral therapy. Many feel ashamed or embarrassed to collect their medication, and some reported being stigmatised by HCWs and pharmacists. At pharmacies, patients reported waiting in line for their HBV medication alongside HIV-positive people, and again experiencing stigma by association with HIV.

When you tell them that HBV is more dangerous than HIV, they don't understand. And when they see those drugs for HIV they think you are HIV-positive. Like last time, my brother, went there to take some drugs at the hospital there for (HBV) and he was in the same line with HIV patients. (Female, age 33)

Before I was put on medication all was well, but after he [husband] discovered that the medication which I was given, these ARVs, then he said no, then you are lying you are positive [HIV]. You have to find someone who is Hepatitis B like you are because it's not an easy thing. It will be very difficult for me to understand you and be with you. Allow me to find someone who is negative since me am negative, $[\ldots]$. I can't be staying with someone who is taking ARVs. (Female, age 30)

\section{SUMMARY OF BARRIERS TO HBV CONTACT TESTING IN LUSAKA, ZAMBIA (SURVEY AND FGD DATA INTEGRATION)}

Five thematic categories have been identified as barriers to HBV contact testing in Lusaka, Zambia, based on converged data from HBV patient surveys and FGDs, including (1) low disclosure of HBV status, particularly to contacts other than primary partners, (2) low awareness of HBV in the community, (3) low knowledge about HBV both among patients with HBV and in the community, (4) enacted and internalised HBV stigma and HBV-HIV cross-sectional stigma, and (5) other barriers. Integrated results are presented in table 3 .

\section{DISCUSSION}

\section{Main findings}

Among HBV monoinfected adults in Zambia, disclosure of HBV status to at least one contact was relatively common (89\%) and yielded new diagnoses supporting the feasibility and acceptability of contact testing to raise awareness of HBV status. Although contact testing was helpful, the majority of contacts, who are presumed to be at increased risk of HBV, were not reached through this approach. Low HBV awareness and knowledge, as well as stigma, emerged as obstacles to communication about HBV between index patients and their contacts. Wider awareness of the disease and a better understanding of barriers to seeking an HBV test are needed to optimise the use of this important public health intervention.
Our primary finding was that disclosure to contacts of HBV index patients resulted in HBsAg testing and identification of new diagnoses supporting WHO hepatitis testing guidelines. ${ }^{30}$ The proportion of those contacts who were tested and received results who were reported to be HBsAg-positive was $11.9 \%$, which is $2-3$ times that of estimates of $\mathrm{HBV}$ in the general adult population in Lusaka $(\sim 4.0 \%)$ although direct comparison was not performed. Disclosure to first-degree family members who were not partners was lower than partners, perhaps because Zambia is a large country and many participants have only sporadic in-person contact with many relatives. Disclosure to household members that were neither partners nor close blood relatives was uncommon, possibly because index patients feared provoking anxiety and stigma in the household. Mechanisms through which HBV is transmitted in the household are incompletely understood, ${ }^{31}$ which could make it difficult for nurses or counsellors to strongly encourage disclosure to and testing of household members.

Another important finding was that stigma appears to be a significant barrier to $\mathrm{HBV}$ disclosure and testing in Zambia, including stigma by HBV's association with HIV. In our study, a small increase in stigma score was associated with a relatively strong decrease in disclosure building on studies in Asia and among immigrants in the USA. ${ }^{15} 1723{ }^{32}$ In FGDs, participants reported both internalised and enacted stigma related to $\mathrm{HBV}$ and had specific concerns over being prescribed antiviral drugs identical to those taken for HIV infection in Zambia. Health workers with HBV in our study reported experiencing stigma at their workplaces, suggesting that health workers should be a major target for HBV sensitisation and education as HBV treatment is scaled up. Unfortunately, HBV immunisation is not routine for healthcare workers in Zambia however, having a needle-stick injury was found to be associated with greater odds of vaccination. ${ }^{33}$ Finally, our data are some of the first to describe HBV stigma by association with HIV in Africa. As both are chronic viral infections that can be treated by some of the same drugs, HBV services may be integrated with HIV in settings with strong HIV/AIDS programmes like Zambia. Although data are lacking, integration of HBV testing and care within an HIV care context may be cost saving and efficient. A better understanding of how HIV-associated stigma $^{3435}$ could impact HBV is needed to guide scale up of HBV activities in these settings.

\section{Strengths and weaknesses}

We believe this paper will be relevant to public health officials and policymakers in low-income and middle-income settings for several reasons. First, these data support the utility and feasibility of a contact testing approach to HBV. In Zambia, household testing of contacts of HIV and tuberculosis cases is recommended by the Ministry of Health ${ }^{36}$ and a similar approach could be taken for HBV. Rapid point-of-care tests are increasingly available for HBV and could be easily integrated into 
Table 3 Summary of barriers to hepatitis B virus (HBV) contact testing in Lusaka, Zambia

\begin{tabular}{|c|c|c|}
\hline Barrier & Surveys & Focus groups \\
\hline $\begin{array}{l}\text { Disclosure of HBV } \\
\text { status }\end{array}$ & $\begin{array}{l}42 \% \text { of contacts were disclosed to } \\
88 \% \text { of patients with HBV disclosed } \\
\text { to } \geq 1 \text { contact (average number of } \\
\text { contacts } 9.8 \text { ) } \\
\text { Most common disclosure: primary } \\
\text { partner } \\
\text { A one-unit increase in stigma score } \\
\text { was associated with a } 12 \% \text { reduction } \\
\text { in the odds of disclosure }\end{array}$ & $\begin{array}{l}\text { Reported low levels of disclosure, particularly to contacts } \\
\text { other than primary partner } \\
\text { Most commonly if disclosure occurs, it is to primary partners } \\
\text { and possibly children } \\
\text { Accusation of promiscuity on disclosure and negative } \\
\text { impact on partner relationship } \\
\text { Stigma, particularly due to association with HIV reported as } \\
\text { the most common factor in disclosure }\end{array}$ \\
\hline $\begin{array}{l}\text { Low awareness of } \\
\text { HBV }\end{array}$ & Not measured in surveys & $\begin{array}{l}\text { Non-existent or low awareness of HBV in community; myths } \\
\text { and assumptions made based on HIV 'knowledge' } \\
\text { Many current patients reported learning about HBV when } \\
\text { testing, eg, due to the mandatory testing, eg, when applying } \\
\text { for a certain job or due to the work-related injury }\end{array}$ \\
\hline $\begin{array}{l}\text { Other } \\
\text { Financial } \\
\text { concerns } \\
\text { Lifelong care on } \\
\text { diagnosis } \\
\text { Perceived } \\
\text { low value to } \\
\text { knowing one's } \\
\text { status while still } \\
\text { asymptomatic }\end{array}$ & Not measured in surveys & $\begin{array}{l}\text { Concerns related to the healthcare, medication and related } \\
\text { costs (eg, transportation), particularly when faced with } \\
\text { lifelong daily treatment } \\
\text { Fears related to HBV diagnosis and its impact (stigma, } \\
\text { disclosure, costs, relationships, lifestyle changes, fear of } \\
\text { unknown, other) } \\
\text { Perceived low value of knowing HBV status while } \\
\text { asymptomatic }\end{array}$ \\
\hline
\end{tabular}

community-based interventions. ${ }^{30}$ Second, this is one of the first studies on HBV stigma in Africa, and our data suggest that dedicated efforts may be needed to prevent or reduce $\mathrm{HBV}$ stigma as programmes are introduced and scaled up. In low and middle-income countries (LMICs), many individuals with $\mathrm{CHB}$ infection were 
infected at birth/early childhood unlike upper-income settings where $\mathrm{HBV}$ is transmitted through sharing needles or sex $^{3}$; therefore, health messages that avoid painting $\mathrm{HBV}$ as a life-threatening sexually transmitted infection and that normalise HBV infection may be needed. Finally, our HBV testing cascade could be replicated over time within HBV treatment programmes to track progress in testing contacts.

Our analysis has several weaknesses that deserve discussion. First, our HBV disclosure and testing cascade relied entirely on index patient report that is subject to social desirability and recall biases. Index patients may have overstated the degree to which they disclosed to others. FGDs supported the finding that most patients managed to disclose to at least one contact. On the other hand, reliance on the index patient's report may have led us to underestimate uptake of testing as some contacts may have gone for HBsAg testing without informing the index patient. Second, as our analysis was cross-sectional, we could only identify correlates of disclosure and not causative factors. Finally, the population studied had relatively high education levels and the cohort was hospital-based including patients with more advanced disease; therefore, external validity to other HBV populations could be reduced. This reflects the realities in Zambia, where access to HBV testing and care is not universal yet and selection bias may limit the external validity of our results.

\section{Implications for clinicians and policymakers}

While the majority of HBV-positive individuals in Africa may have acquired the infection in early childhood, ${ }^{37}$ horizontal transmission in adulthood, through drug use or sexual contact, also contributes to the overall prevalence. HBV contact disclosure and testing can both identify undiagnosed CHB infections and provide opportunities for prevention using the vaccine. Our data provide evidence for the feasibility of contact disclosure and testing in settings like Zambia; however, dedicated efforts are needed to raise awareness and knowledge about HBV and viral hepatitis in general. More research is needed to understand HBV stigma in Africa, particularly in countries with large HIV epidemics. Future studies in this area should explore impact of different types of stigma, as well as pathways and effect of stigma on disclosure and testing among HBV index patients and their contacts.

Contributors MV, ES, AK, AH, JMT and JD-0 were responsible for developing the design of the study. MV, AK, SF and AM were responsible for overseeing study implementation and data collection. MV, SF, AM and AH were responsible for conducting the analyses, interpreting the results and drafting the manuscript. MV, AH, JMT and JD-0 critically revised the manuscript. All authors have read and approved the final manuscript.

Funding This research was supported by the National Institute on Minority Health and Health Disparities (grant number T37MD001448), the Fogarty International Center (grant number K01TW009998), and the Eunice Kennedy Shriver National Institute of Child Health (grant number K23HD090993) and Human Development at the United States National Institutes of Health. The Hepatitis B UTH Cohort is also supported by the UAB School of Medicine.
Competing interests None declared.

Patient consent Obtained.

Ethics approval The University of Zambia Biomedical Research Ethics Committee and the University of Alabama at Birmingham Institutional Review Board.

Provenance and peer review Not commissioned; externally peer reviewed.

Data sharing statement The authors have full control of all primary data and agree to allow the journal to review their data if requested.

Open access This is an open access article distributed in accordance with the Creative Commons Attribution Non Commercial (CC BY-NC 4.0) license, which permits others to distribute, remix, adapt, build upon this work non-commercially, and license their derivative works on different terms, provided the original work is properly cited, appropriate credit is given, any changes made indicated, and the use is non-commercial. See: http://creativecommons.org/licenses/by-nc/4.0/.

\section{REFERENCES}

1. Lok AS, McMahon BJ. Chronic hepatitis B. Hepatology 2007;45:507-39.

2. World Health Organization. Hepatitis B Fact sheet, 2017.

3. World Health Organization. Global Hepatitis Report, 2017.

4. Stanaway JD, Flaxman AD, Naghavi M, et al. The global burden of viral hepatitis from 1990 to 2013: findings from the Global Burden of Disease Study 2013. Lancet 2016;388:1081-8.

5. Mitchell T, Armstrong GL, Hu DJ, et al. The increasing burden of imported chronic hepatitis B-United States, 1974-2008. PLoS One 2011;6:e27717.

6. WHO Guidelines Approved by the Guidelines Review Committee. WHO Guidelines on Hepatitis B and C Testing. Geneva: World Health Organization Copyright (c) World Health Organization, 2017;2017.

7. Shi Y, Wu YH, Wu W, et al. Association between occult hepatitis B infection and the risk of hepatocellular carcinoma: a meta-analysis. Liver Int 2012;32:231-40.

8. Lemoine M, Shimakawa Y, Njie R, et al. Acceptability and feasibility of a screen-and-treat programme for hepatitis $b$ virus infection in the gambia: the prevention of liver fibrosis and cancer in Africa (PROLIFICA) study. Lancet Glob Health 2016;4:e559-e567.

9. Ferrante JM, Winston DG, Chen PH, et al. Family physicians' knowledge and screening of chronic hepatitis and liver cancer. Fam Med 2008;40:345-51.

10. Kwon SY, Lee CH. Epidemiology and prevention of hepatitis B virus infection. Korean J Hepatol 2011;17:87-95.

11. Blanas DA, Nichols K, Bekele M, et al. Adapting the andersen model to a francophone west african immigrant population: hepatitis $b$ screening and linkage to care in New York City. J Community Health 2015;40:175-84.

12. Yu L, Wang J, Zhu D, et al. Hepatitis B-related knowledge and vaccination in association with discrimination against Hepatitis $B$ in rural China. Hum Vaccin Immunother 2016;12:70-6.

13. Huang J, Guan ML, Balch J, et al. Survey of hepatitis B knowledge and stigma among chronically infected patients and uninfected persons in Beijing, China. Liver International 2016;36:1595-603.

14. Lee H, Fawcett J, Kim D, et al. Correlates of hepatitis B virus-related stigmatization experienced by asians: a scoping review of literature. Asia Pac J Oncol Nurs 2016;3:324-34.

15. Dam L, Cheng A, Tran P, et al. Hepatitis B stigma and knowledge among vietnamese in Ho Chi Minh City and Chicago. Can $J$ Gastroenterol Hepatol 2016;2016:1-8.

16. Sievert K, O'Neill $\mathrm{P}$, Koh $\mathrm{Y}$, et al. Barriers to accessing testing and treatment for chronic hepatitis $b$ in afghan, rohingyan, and south sudanese populations in Australia. J Immigr Minor Health 2018;20:140-146.

17. Cheng S, Li E, Lok AS. Predictors and barriers to hepatitis b screening in a midwest suburban Asian population. J Community Health 2017;42:533-43.

18. Li D, Tang T, Patterson M, et al. The impact of hepatitis B knowledge and stigma on screening in Canadian Chinese persons. Can J Gastroenterol 2012;26:597-602.

19. Hu KQ, Pan CQ, Goodwin D. Barriers to screening for hepatitis $B$ virus infection in Asian Americans. Dig Dis Sci 2011;56:3163-71.

20. Zambian Ministry of Health. Zambia consolidated guidelines for prevention and treatment of HIV infection. Lusaka, Zambia, 2018.

21. Holmes CB, Sikazwe I, Sikombe K, et al. Estimated mortality on HIV treatment among active patients and patients lost to follow-up in 4 provinces of Zambia: Findings from a multistage sampling-based survey. PLoS Med 2018;15:e1002489-e89. 
22. Raimondo G, Caccamo G, Filomia R, et al. Occult HBV infection. Semin Immunopathol 2013;35:39-52.

23. Huang J, Guan ML, Balch J, et al. Survey of hepatitis B knowledge and stigma among chronically infected patients and uninfected persons in Beijing, China. Liver Int 2016;36:1595-603.

24. Thio CL. Hepatitis $B$ in the human immunodeficiency virus-infected patient: epidemiology, natural history, and treatment. Semin Liver Dis 2003;23:125-36.

25. Creswell JW, Plano Clark VL. Designing and conducting mixed methods research. 2 edn. CA: Thousand OaksSage Publications, 2010.

26. Molina Y, Choi SW, Cella D, et al. The stigma scale for chronic illnesses 8-item version (SSCl-8): development, validation and use across neurological conditions. Int J Behav Med 2013:20:450-60.

27. McMahon BJ. Editorial commentary: sliding down the cascade of care for chronic hepatitis B Virus Infection. Clin Infect Dis 2016;63:1209-11.

28. Attride-Stirling J. Thematic networks: an analytic tool for qualitative research. Qualitative Research 2001;1:385-405.

29. Braun V, Clarke V. Using thematic analysis in psychology. Qual Res Psychol 2006;3:77-101.

30. World Health Organization. Guidelines on hepatitis $B$ and $C$ testing: policy brief, 2016.
31. Abdool Karim SS, Thejpal R, Coovadia HM. Household clustering and intra-household transmission patterns of hepatitis $B$ virus infection in South Africa. Int J Epidemiol 1991;20:495-503.

32. Blanas DA, Nichols K, Bekele M, et al. Adapting the Andersen model to a francophone West African immigrant population: hepatitis B screening and linkage to care in New York City. J Community Health 2015;40:175-84.

33. Mungandi N, Makasa M, Musonda P. Hepatitis B vaccination coverage and the determinants of vaccination among health care workers in selected health facilities in Lusaka district, Zambia: an exploratory study. Ann Occup Environ Med 2017;29:32.

34. Mahajan AP, Sayles JN, Patel VA, et al. Stigma in the HIV/AIDS epidemic: a review of the literature and recommendations for the way forward. AIDS 2008;22(Suppl 2):S67.

35. Murray EJ, Bond VA, Marais BJ, et al. High levels of vulnerability and anticipated stigma reduce the impetus for tuberculosis diagnosis in Cape Town, South Africa. Health Policy Plan 2013;28:410-8.

36. Zambian Ministry of Health. Zambia consolidated guidelines for treatment and prevention of HIV infection. Lusaka, Zambia, 2016.

37. Kiire CF. The epidemiology and prophylaxis of hepatitis B in subSaharan Africa: a view from tropical and subtropical Africa. Gut 1996;38:S5-12. 